\title{
REKENAARS AS 'N HULPMIDDEL IN VERPLEEGKUNDIGE ADMINISTRASIE
}

\author{
MIRINDA COETSEE
}

\section{SUMMARY}

Over the last few years pressure has been brought to bear on nurse managers worldwide to cut costs in their departments and to freeze posts, while maintaining a high quality of nursing care.

Computers can be utilised in nursing administration to cut costs and to help increase productivity. There are three main areas in which computers can serve as an aid to nursing administration. A word-processor in the manager's office can save a lot of time, the spreadsheet is invaluable for financial planning and a data base, which can be likened to an electronic filing cabinet, quickly produces information which would previously have taken hours to compile.

There are computer programs, such as the Nurse Manager which are designed specifically for nursing administration. the above program combines the latest micro-computer technology with a patient classification system to provide a powerful staff management tool.

\section{INLEIDING}

Die belangrikheid van rekenaars as hulpmiddels in die daaglikse funksionering van 'n hospitaal word vandag al hoe meer besef. Sagteware is beskikbaar vir onder andere, finansiële beplanning, kliniese inligting, pasiëntakuutheidsprofielklassifikasie en verpleegpersoneelbeplanning en skedulering. Sagteware is beskikbaar wat hospitaaladministrasie in staat stel om die produktiwiteit van elke hopsitaaldepartement te meet om sodoende 'n hospitaal meer koste-effektief te beheer.

Gedurende die afgelope paar jaar word daar wêreldwyd al hoe meer druk op verpleegdiensbestuurders uitgeoefen om koste in hul departemente te bekamp, poste te bevries en nogtans te verseker dat 'n hoë gehalte van verpleegsorg gehandhaaf word.

Dit is veral met die oog op kostebekamping en produktiwiteit dat hierdie artikel poog om 'n oorsig te gee van hoe 'n rekenaar in verpleegadministrasie gebruik kan word. 'n Sagtewareprogram wat spesifiek vir verpleegadministrasie ontwerp is, word ook bespreek

Dit is vandag algemene kennis dat die rekenaar produktiwiteit verbeter en analitiese vermoëns verskerp. Die rekenaar verminder of elimineer vervelige, herhalende aktiwiteite wat hulle tot

Mirinda Coetsee BA Verpl. (PU vir CHO) MSN (Texas)

DVO (Pretoria) DSM (Alabama)

Konsultant, Ernst \& Whinney Be-

stuursdienste Beperk, Posbus 656 .

Kaapstad, 8000. allerlei foute leen. Rekenaars help 'n mens om meer in minder tyd te verrig - hulle vervang al daardie aktiwiteite wat deur tikmasjiene, optelmasjiene, potlood en papier gedoen word en gewoonlik 'n groot hoeveelheid tyd in beslag neem.

Daar is vandag soveel sagtewareprogramme op die mark dat die verpleegdepartement in die hospitaal, met 'n bietjie ondernemingsgees, die rekenaar op 'n doeltreffende wyse in die daaglikse funksionering van die departement kan aanwend. Brown (1983) het tereg opgemerk:

We live in an era where technological change is endemic, leadership styles are changing and the nurses' roles are expanding to accomodate these changes. The computer is no longer a tool for research and education or purely business. It has for some time played a small part within the health care field as fiscal management of the hospital business office. With further introduction, this health care distributed system has become an integrated network of applications, functions and procedures, serving almost every hospital department. Its biggest impact in recent years has been in the nursing department, with order entry as its prime function. With this interface organisational changes occurred and the ability for nurse managers to work with historical data has become very important.

\section{AREAS VAN GEBRUIK}

Daar is basies drie verskillende areas waarin die rekenaar as 'n hulpmiddel in verpleegadministrasie benut kan word.

\section{Woordverwerker}

'n Besige kantoor wat allerlei korrespondensie, memo's, verslae en dokumente voortbring, kan vandag moeilik sonder 'n woordverwerker 'n hoë mate van produktiwiteit toon. Die rekenaar vervang die tikmasjien se funksies en doen veel meer. So, byvoorbeeld, kan die hospitaal se staande opdragte en prosedurehandleidings, die hospitaalbeleid, reëls en regulasies, posbeskrywings, die handleiding vir rampbeplanning en ander hospitaalgeskrifte op die woordverwerker gedoen word. 'n Dokument wat professioneel en netjies lyk kan gou voortgebring word.

Verder kan die kantoor 'n voortgesette lys van probleme of projekte, of 'n lys van oogmerke wat bereik moet word op die woordverwerker hou. Dit is ideaal om telefoonlyste en vorms wat gereeld gebruik moet word op die woordverwerker te hou.

Wanneer veranderings op die dokument aangebring moet word, kan dit maklik met die druk van 'n paar knoppies gedoen word. Gedeeltes kan uitgelaat of toegevoeg word; sekere woorde. sinne of paragrawe kan binne die teks rondbeweeg word. Sommige sagteware skep die moontlikheid om in hele biblioteek van woorde, terme, sinne of selfs paragrawe wat gereeld gebruik word op te bou. Byvoorbeeld, indien die tikster dikwels die $\sin$ Algemene Hospitaal, Eikelaan, Bossieslaagte moet tik, kan sy 'n makrokode daarvoor skep, sê maar A. Wanneer sy telkens die hele sin moet tik, tik sy nou net die letter $\mathbf{A}$ en die rekenaar skryf die res. 
Nog 'n nuttige funksie van woordverwerkers is hul vermoë om die dokument na smaak voort te bring. Rangskikking van gedeeltes van die teks, voetnotas, spesiale karakters, vormbriewe en enige ander spesiale druktegniek kan deur die meeste woordverwerkers gedoen word. Spesiale druktegnieke, soos vetgedrukte letters om sekere gedeeltes van die teks skerp onder die leser se aandag te bring, kan effektief deur die rekenaar gedoen word.

Wanneer tyd en koste in berekening gebring word, is 'n woordverwerker noodsaaklik in enige kantoor waar 'n massa tikwerk voortgebring word.

\section{Sigblad}

'n Sigblad (spreadsheet) is niks meer as 'n groot elektroniese vel werkpapier wat gebruik word om finansiële inligting te verwerk nie. Sigblaaie bestaan uit horisontale rye en vertikale kolomme wat 'n rooster of 'n matriks vorm. Die interseksie van 'n ry en 'n kolom vorm 'n sel waarin numeriese inligting verwerk word. Die belangrikste kenmerk van 'n sigblad is dat dit moontlikheid inhou om 'n finansiële model van enige situasie te skep. Wanneer al die data ingevoer is en die matematiese verhoudings geformuleer is, kan daar op 'n verskeidenheid van maniere met die data gewerk word. Nou kan wat sal gebeur indien vrae aan die rekenaar gevra word en deur een waarde te verander, sal die rekenaar onmiddellik die resultate van al die ander waardes herbereken. Die volgende is 'n voorbeeld van hoe 'n sigblad in verpleegministrasie benut kan word.

$\mathrm{U}$ word aangesê om in die volgende jaar in sekere bedrag in $u$ departement te besnoei. Die rekenaar sal nou op, byvoorbeeld, die volgende vrae antwoorde gee: Wat sal gebeur indien ek ses assistentposte teen $\mathrm{X}$-skaal afskaf en een geregistreerde verpleegkundige teen Y-skaal aanstel? Dit stel $u$ in staat om probleme vinnig op te merk en tendense te voorspel. Deur al die data in 'n matriksvorm op 'n skerm te hê, het mens 'n baie beter begrip van die syfers en watter invloed hulle op mekaar uitoefen. Die vermoë om byvoorbeeld veranderinge in die departement se begroting te simuleer, stel mens in staat om nuwe benaderings op die skerm te beproef voordat dit geïmplementeer moet word.

Die sigblad kan ook die verpleegkundige in bevel van die saal se taak vergemaklik. Daar kan byvoorbeeld beter kontrole oor voorrade in die saal uitgeoefen word, en kan sy allerlei statistiek begin versamel wat haar 'n goeie aanduiding van produktiwiteit en effektiewe saalbeheer kan gee.

Enige aspekte van die verpleegdepartement se funksies wat met syfers te make het kan met die sigblad hanteer word. Klein navorsingsprojekte waaroor die departement inligting wil bekom kan deur die sigblad geanaliseer en uiteengesit word. Voorbeelde van moontlike analises is die tyd wat verpleegpersoneel spandeer in direkte pasiëntesorg. indirekte sorg (verslag skryf, beplanning) en persoonlike tyd; navorsingsdata oor pasiënte wat intraveneuse voeding ontvang; of enige ander data wat op 'n objektiewe wyse versamel en verwerk kan word.

Sommige sigbladsagtewarepakette laat mens ook toe om die getabuleerde inligting in grafieke om te sit. Dit is soms moeilik en tydrowend om getabuleerde inligting te lees en te analiseer. As die inligting egter in $n$ bepaalde soort grafiek weergegee kan word, word die betekenisvolle inligting in die data duidelik weerspieël.

Enige finansiële beplanning in die verpleegdepartement, soos die motivering vir die aankoop van items. die afskryf van items, die invloed daarvan op die finansiële staat, word met die gebruik van die sigblad vergemaklik. Dit is veral hier waar die verpleegdepartement besondere beheer kan uitoefen. Die gebruik van hospitaalvoorrade en medikasie kan met die pasiëntsensus en die akuutheidsprofiel van pasiënte in verband gebring word en tendense kan oor 'n verloop van maande getrek word.

\section{Databasis}

Enige inligting wat tans in lêers, boeke of op 'n ander metode geliasseer word en soms ure in beslag neem om op te soek of te verwerk, kan in 'n databasis gevoer word en op enige wyse in in drukstuk uiteengesit word.

'n Databasis is 'n elektroniese liasseerkabinet. Hierdie sagtewarepakette vervul drie basiese funksies. Eerstens skep dit die moontlikheid om data in "n gerieflike vorm te stoor. Ten tweede kan data na voorkeur geprosesseer word, en derdens kan die data in "n drukstuk vir verskillende situasies uiteengesit word. 'n Databasis van al die verpleegpersoneel kan byvoorbeeld gebou word, en inligting kan nou vinnig uit die rekenaar verkry word - soos 'n alfabetiese lys van alle personeel, 'n lys van geregistreerde versus nie-geregis- treerde personeel, 'n lys van personeel gerangskik volgens die eenhede waarin hulle werk. Die persoonlike inligting van die verpleegpersoneel soos opleiding, registrasie. ervaring, en so meer kan in die rekenaar gevoer word. $U$ kan nou vinnig antwoorde op vrae kry wat andersins heelwat tyd in beslag sou neem. Byvoorbeeld:

Wie van die geregistreerde personeel het meer as tien jaar diens? Wie van die personeel het 'n addisionele kwalifikasie in administrasie? Hoeveel van die personeel woon in 'n radius van vyf kilometer van die hospitaal af? Hoeveel van die studentverpleegkundiges moet nog hul praktiese opleiding in die mediese sale doen? Watter indiensopleiding is deur wie bygewoon? Wie van die personeel se beurt is dit om na ' $n$ konferensie gestuur te word

Nuwe inligting kan baie maklik ingevoer word, inligting kan verander word en verouderde inligting kan met die druk van 'n paar kontroles verwyder word.

Die databasis is dus nog in effektiewe metode om massa-inligting te stoor. maklik te bekom, te beheer. en die produktiwiteit van die departement te verhoog

\section{DIE VERPLEEGDIENS- BESTUURDER}

Die verpleegdepartement het die meeste personeel in die hospitaal, en dus die grootste uitgawe (soms tot meer as $60 \%$ van die totale hospitaalbegroting). Derhalwe word daar veral in die jongste tyd wêrelduyd op verpleegdiensbestuurders druk uitgeoefen om poste te bevries om sodoende die koste van verpleegdepartemente te verlaag. Dit is moeilike posisie vir verpleegdiensbestuurders want daar word dan nog. ondanks verminderde personeel, van hulle verwag om verpleegsorg van hoë gehalte te handhaaf. Om hierdie uitdagings die hoof te kan bied. is al hoe meer navorsing na pasiëntklassifikasiestelsels gedoen om die betroubaarheid en geldigheid om personeelbehoeftes wat op pasiëntakuutheidsprofiele gebaseer is. op in wetenskaplike wyse te bepaal.

Die verpleegdiensbestuurder is in rekenaarprogram wat spesifiek vir verpleegadministrasie ontwerp is. Dit is ' $n$ omvattende program wat die nuutste ontwikkeling in optiese merkleser- en mikrorekenaartegnologie met in pasiëntklassifikasiestelsel kombineer om verpleegadministrasie van in kragtige bestuurshulpmiddel te voorsien. 
Die Verpleegdiensbestuurder bereken die personeelvoorsiening vir elke eenheid. Dit word gedoen met inagneming van die sensus, akuutheid van die pasiënte, die tydstandaarde wat vooraf bepaal is om die verpleegsorg te verleen, die opleidingsvlak van die personeel en die spesifieke dienstyd (byvoorbeeld $07 \mathrm{~h} 00$ $-13 \mathrm{~h} 00)$.

Die verpleegdiensbestuurder stel die verpleegdepartement dus in staat om 'n noukeurig berekende data-analise te doen. Personeelvoorsiening word fyn gekontroleer, pasiëntprofiele vir enige tydperk kan nagegaan word, geskeduleerde, werklike en vereiste personeel kan vergelyk word, die meng van personeel (verskillende opleidingsvlakke) en die daaglikse op-diens-patrone kan vir beplanningsdoeleindes geanaliseer word.

Personeelvoorsiening wat op pasiëntbehoeftes gebaseer is, word gehandhaaf en personeel word dus meer effektief gebruik en produktiwiteit kan nou op 'n voortgesette grondslag gemeet word.
Die verpleegdiensbestuurder het dus spesifieke inligting beskikbaar om langtermynbeplanning vir personeel te doen. Al hierdie verskillende analises stel die verpleegdiensbestuurder in staat om verpleegpraktyke in die hospitaal te evalueer en ingeligte besluite te neem.

Wanneer 'n pasiëntklassifikasiestelsel by 'n hospitaal in werking is, kan nog 'n sagtewareprogram gebruik word om die maandelikse wissellys uit te maak. Die rekenaar word gevoer met spesiale versoeke en spesifieke inligting soos, verlof, blok vir studente, indiensopleidingstye, kongresdae, 8 uur- en 10 uurskofte indien die hospitaal dit het, en die rekenaar lewer die wissellys. Wanneer die tyd wat maandeliks in elke saal gespandeer word om afdienstye uit te maak, in ag geneem word, kan die waarde van so 'n rekenaarprogram nie onderskat word nie. Die program dui enige onreëlmatighede, soos siekverlofpatrone, aan en is ' $n$ verdere hulpmiddel in personeelvoorsiening en -beplanning

\section{SAMEVATTING}

Een persoonlike rekenaar met 'n paar basiese sagtewareprogramme kan 'n besige verpleegadministrasiekantoor in 'n area omskep wat glad funksioneer. Aangesien die verpleegdepartement die grootste werkskomponent van 'n hospitaal verteenwoordig moet verpleegdiensbestuurders noodwendig aandag skenk aan die koste wat daaraan verbonde is. 'n Betroubare pasiëntklassifikasiestelsel en 'n persoonlike rekenaar kan verpleegdiensbestuurders help om optimum verpleegvoorsieningsvlakke daar te stel wat verband hou met die kwaliteit van pasiëntsorg, binne die raamwerk van hedendaagse verpleegpraktyke.

Daarbenewens vervul die rekenaar 'n rol in verpleegproduktiwiteit en kostebekamping, wat vandag van uiterste belang in enige hospitaal behoort te wees.

\section{VERWYSINGS}

Brown. J.L (1983) The use of computer systems in nursing administration in M. Scoles; Y. Bryant: B Barber (eds) The impact of computers on nursing. North Holland. Elsevier Science Publishers

\section{Kommunikasie - vervolg van $p .33$}

talente, unieke belangstellings en gesigspunte. Basies gaan ons ook met die sterwende mens praat vir dieselfde rede as wat ons met die lewende mens praat - uit ons belangstelling in hom as mens. Ons wil hom leer ken en as mens waardeer en respekteer.

In die eerste plek, praat met hulle oor daardie aspekte wat ons in staat sal stel om hulle as mens beter te verstaan en ken - oor hulle werk, hulle stokperdjies, hulle belangstellings en hulle familie. Tweedens, is dit noodsaaklik dat die lydende mens toegelaat sal word om beide rigting aan die gesprek te gee asook om die gesprek na sy goeddenke te beëindig. Die kern van die saak is nie dat ons altyd soveel aan die sterwendes en hulle dierbares te sê het nie, maar dat ons eerder na hulle sal luister en hulle wisselende emosies en stemminge sal volg en dienooreenkomstig optree. Dit impliseer dus pasiënt-gesentreerde begeleiding.

Om te sterwe is baie moeiliker as wat meeste mense dink. Die lewe word op hierdie oomblik ook meer kosbaar. Vir haie mense is dit ' $n$ moelike opgawe om aan hulle eie dood te dink en dit tegemoet te gaan. Daarom vind baie dit ook moeilik om daaroor te praat. Hierdie huiwering vir die eie lewenseinde is te verstane. Die Bybel wys nie verniet na die dood as die laaste vyand nie. Selfs 'n gelowige kan daarmee veel moeite ondervind, dit kan selfs in 'n geweldige geloofskrisis uitmond. Hulle gaan werklik deur 'n dal van doodskaduwee na hulle ewige lewe (Vègh, 1982:3).

Volgens Végh (ibid:3) is sterwensbegeleiding in wese die Christelike handreiking aan iemand wat in die grenssituasie van sy lewe verkeer en deur die dal van doodskaduwee na sy ewige lewe gaan. Ten einde dan met die sterwende en treurende mens in gesprek te tree, is dit nodig om 'n grondige kennis te hê van die dinamika wat sy sterwe en dood en treursmart ten grondslag lê.

\section{Slot}

Om te sterwe is 'n komplekse gebeure wat die mens in sy totaliteit tref, na siel. gees en liggaam, daarom omsluit sterwensbegeleiding dan ook die totale versorging van die sterwende na siel, gees en liggaam. Daar sal nie hier verder op die dinamika en begeleidingsaspekte ingegaan word nie.

Ter afsluiting word daar egter gewys op Robert Gram (1982:9) se realistiese siening van die Bybel omtrent die einde van ons aardse lewe: Dying is not described as natural, euphoric, or intrinsically meaningful. Paul called it the enemy. Judging by his angiush in the garden of Gethsemane, our Lord viewed it as an inexplicable breach with all $\mathrm{He}$ knew and loved.

From a biblical perspective, fear of dying is overcome solely by the hope of the Resurrection. Changing social values or giving death a psychological face-lift does not alleviate our deepest dread. We are helped only when we believe that the Easter event symbolizes our ultimate destiny. Jesus' resurrection indicates that terminal illness is never really terminal. Not even death can separate us from God's love.

\section{BIBLIOGRAFIE}

1. Allen, J.E. and Gluckstein, L.M. (1979) Interviewing and parient care. New York. Oxford

2. Bornman. E.S.: Bornman. N.C. (1972) Speech com munication: an interpersonal approach. New York Harper \& Row.

3. Clarck, Jill, M. (1981) Communication in nursing Nursing Times, Vol. 97 (1): 12 - 18. Jan. 1.

4. De Klerk. W.J. (1971). Die psigologie van sterwe. Potchefstroom. P.U. vir C.H.O

5. De Villiers. Fredrika, M.J. (1977) Sterwensbegeleiding Johannesburg. Perskor.

6. Gram. R. (1982) The myth of meaningful death. The Church Herald. March. 1982:8-9

. Kübler-Ross. Elizabeth. (1966). On death and dying. New York. MacMillan.

8. Murray, R. B. \& Zentner. J.P. (1979). Nursing concepts for health promotion. New York Prentice-Hall

9. O'Brien. Maureen, J. (1974) Communications and rela. tionships in nursing. Saint Louis. Mosby.

10. Sporken, P. (1972) De Laaste levensfase - stervenshulp, euthanasia. Bilthoven. Amboboeken.

11 Travelbee. Joyce. (1972). Interpersonal relationships. Philadelphia. Davis.

12. Végh. J. Sterwensbegeleiding: een christelike handreiking. Centraal Weekblad. 12 Mei, 30:19:3.

13. Venter, C.J.H. (1972). Die pastorale dimensie in begeleiding van sterwendes. Potchefstroom. P.U. vir C.H.O. 